\title{
The financial content of inflation risks in the euro area *
}

\author{
Philippe Andrade ${ }^{\dagger} \quad$ Valère Fourel $^{\ddagger} \quad$ Eric Ghysels $^{\S}$ \\ Julien Idier ${ }^{\pi}$
}

December 3, 2012

\begin{abstract}
Recent studies emphasize that survey-based inflation risk measures are informative about future inflation and thus useful for monetary authorities. However, these data are typically available at a quarterly frequency whereas monetary policy decisions require a more frequent monitoring of such risks. Using the ECB survey of professional forecasters, we show that high-frequency financial market data have predictive power for the low-frequency survey-based inflation risk indicators observed at the end of a quarter. We rely on MIDAS regressions to handle the problem of mixing data with different frequencies that such an analysis implies. We also illustrate that upside and downside risks react differently to financial indicators.
\end{abstract}

*The third author acknowledges support from the Banque de France. We thank Béatrice Saes-Escorbiac and Aurélie Touchais for excellent research assistance. This paper does not necessarily reflect the views of the Banque de France nor the ones of the ECB.

†Banque de France, Monetary Policy Research unit \& CREM, 31 rue Croix des Petits-Champs, 75001 Paris, FRANCE, e-mail: philippe.andrade@banque-france.fr.

${ }_{\ddagger}^{\ddagger}$ Banque de France, Financial Economics Research unit, 31 rue Croix des Petits-Champs, 75001 Paris, FRANCE, e-mail: valere.fourel@banque-france.fr.

$\S$ Department of Economics, University of North Carolina, Gardner Hall CB 3305, Chapel Hill, NC 275993305, USA, and Department of Finance, Kenan-Flagler Business School, e-mail: eghysels@unc.edu.

TBanque de France \& European Central Bank, Monetary Policy division, Capital Markets, e-mail: julien.idier@ecb.int 


\section{Introduction}

Assessing inflation risks is key to the conduct of monetary policy. To this aim, central bankers regularly resort to surveys of professional forecasters (SPF) to monitor the central tendency in the distribution of future inflation, typically through mean point forecasts. Ang, Bekaert, and Wei (2007) emphasize that the so-called consensus forecast, i.e. the average of professionals' mean point forecast of inflation, is indeed a very good predictor of future inflation realizations. More recently, Andrade, Ghysels, and Idier (2012) develop new surveybased inflation risk indicators which rely on quantiles extracted from individual subjective distributions of future inflation to measure the risk of extreme inflation realizations. They show that these measures are complementary to the usual consensus forecast extracted from surveys as they allow for a distinction between upside and downside inflation risks and as they also bring information about future inflation outcomes in addition to the usual consensus forecast.

SPF data are thus an important source of information to assess the risks to future inflation. However, they suffer from an important drawback which is to be available at a low frequency, typically every quarter. By contrast, monetary policy decisions require a continuous monitoring of macroeconomic conditions. As a matter of fact, central banks also regularly use high frequency financial market data in their decision making process. In this paper, we investigate whether such financial market data are informative for the various survey based inflation risk measures and hence can be used in order to predict survey based inflation risk measures between two subsequent quarters. In addition, and as a byproduct of this analysis linking inflation risk indicators to financial variables, we can get a sense of the economic information these inflation risk measures convey.

More specifically, we resort to Mixed Data Sampling regression (MIDAS) of Ghysels, SantaClara, and Valkanov (2002) to deal with the problem of handling data of different frequencies implied by this empirical exercise. We consider a set of seven daily financial variables that covers the main dimensions of financial markets: oil prices, stock prices, exchange rates, money markets, and bond markets. We assess the predictive power of each variable on a set of five quarterly survey-based inflation risk indicators: a measure of the central tendency of future inflation distribution, a measure of the extremely high inflation risk, a measure of the extremely low inflation risk, a measure of the uncertainty of future inflation, and a measure of the asymmetry of the risk to inflation. We compare both in-sample and out-of-sample 
forecasts of the models using the different financial variables with the usual auto-regressive and random-walk models. We also look at the information brought by the whole set of financial indicators we consider by constructing forecasts combining the ones resulting from each individual model.

We emphasize the following three main results. First, past financial market data have a significant impact on measures of inflation risks. Second, and related, this impact differs across indicators. In particular, upside and downside risks react differently to the same financial variable. Financial indicators thus contain information about the inflation risk uncertainty and asymmetry: observed changes in several financial indicators do not lead to a simple upward translation of the whole distribution of inflation risks, but to changes in the way the risks are distributed around this central tendency. Put it differently, the results illustrate that looking at the MPF only provides an incomplete assessment of perceived inflation risks. Third, daily financial variables help predict the inflation risk indicators both in-sample and out-of-sample. MIDAS regressions using financial data systematically present lower in-sample root-mean-squared errors (RMSE) compared to the ones of a simple autoregressive model or of a random walk model. Moreover, we also show that a simple average of the forecasts drawn from each single financial indicator MIDAS regression can reduce the out-of-sample root-mean-squared forecast errors (RMSFE) by up to $13 \%$ compared to the random walk model for some risk indicators and by up to $15 \%$ compared to a pure autoregressive model. All in all, our results emphasize that high frequency financial data bring information about the evolution of the inflation risk indicators at a frequency that is higher than the one provided in surveys.

Our paper can be related to the studies investigating whether financial variables help predict future inflation. Stock and Watson (2003) find that they are of little help while Bryan, Cecchetti, and Wiggins II (1997) or Cecchetti (2008) find the opposite. These studies do not consider financial data of a higher frequency than the forecasted inflation rate while Monteforte and Moretti (2010) do. They rely on the MIDAS methodology to show that financial data can reduce the forecasting errors of the euro-area inflation rate and therefore are useful in characterizing the inflation risk measured by the average point forecasts of the future inflation rate. Our approach is complementary to theirs as we look at the impact of high frequency financial variables on survey-based inflation risk measures.

Our results that high frequency financial variables help forecast inflation risk measures connect this paper to the work of Ghysels and Wright (2009) who predict the mean point 
inflation forecasts of professionals in the US using financial variables. It also relates to the forecasting literature, where the mixing sampling methodology and the information content of financial market data have been used to improve the forecasts of macroeconomic variables, typically the growth rate of GDP like for instance in Galvao and Clements (2008) or Marcellino and Schumacher (2008).

Our work can also be linked to papers aiming at measuring and understanding inflation risks beyond the central tendency of future inflation distribution. For instance, Engle (1982) focuses on the second moment of future inflation, Garcia and Manzanares (2007) also look at the asymmetry of the distribution of future inflation, and Christensen, Lopez, and Rudebusch (2011) estimate deflation probabilities. We investigate the impact of financial variables on each of these three dimensions of the distribution of future inflation.

Finally and more generally, this study shares some features with Andrade and Le Bihan (2010), and Coibion and Gorodnichenko (2012), who aim at understanding and characterizing the formation of expectations by looking at surveys.

The remainder of this paper is organized as follows. In Section 2, we present the survey-based inflation risk measures we consider. Section 3 describes the MIDAS methodology. Details on the dataset that we use are given in Section 4. We provide and discuss the estimation of the MIDAS regressions in Section 5. Section 6 is devoted to the analysis of in-sample and out-of-sample performances of the models using daily information from financial markets. We conclude in Section 7.

\section{Survey-based measures of inflation risk}

How does one characterize and measure inflation risk? Most of the time, it is resorted to the central tendency in the distribution of future inflation. A standard survey-based measure of this central tendency is the so called consensus forecast, i.e. the average of mean point forecasts (MPF) across individuals, namely:

$$
\operatorname{MPF}_{t}^{h}=\mathrm{E}_{i}\left(m_{i t}^{h}\right)
$$

where $\mathrm{E}_{i}$ is the expectation across individual forecasters $i$, and where $m_{i t}^{h}$ denotes the mean point forecast of inflation made by individual $i$ at date $t$ for a forecasting horizon of $h$ 
quarters.

However, as Kilian and Manganelli (2008) argue, mean point forecasts do not provide the full set of information a central banker would be interested in when he/she has asymmetric preferences on inflation risks. These authors advocate a risk management approach to monetary policy according to which policy decisions are taken not only with respect to mean point forecasts of inflation but also estimates of potential extreme inflation realizations. The question is then how to measure extreme inflation risks. One answer is provided in Andrade, Ghysels, and Idier (2012) who develop such kind of measures, based on survey data. These inflation-at-risk indicators ( $\mathrm{I} @ \mathrm{R})$ complement the standard MPF indicator. In particular, they enable us to explicitly make the distinction between upside and downside risks, i.e. to depart of the assumption that the risks are balanced. Moreover, Andrade, Ghysels, and Idier (2012) show that these indicators have some predictive power for future inflation realizations in addition to the usual MPF.

$\mathrm{I} @ \mathrm{R}$ are defined for a certain risk level $p$, that is the a given risk to see inflation below a certain threshold. More precisely, we consider the risk $p$ such that:

$$
p=\operatorname{Pr}\left\{\pi_{t+h}<q_{i t}^{h}(p) \mid I_{t}^{i}\right\} \quad \text { or } \quad q_{i t}^{h}(p)=\left(F_{i t}^{h}\right)^{-1}(p)
$$

where $\pi_{t+h}$ is inflation at date $t+h, q_{i t}^{h}(p)$ is the quantile in the forecasters $i$ individual distribution associated with risk $p, I_{t}^{i}$ is forecaster's $i$ information set at date $t$ and $F_{i t}$ is the cumulative distribution function of forecaster $i$ at date $t$. The inflation-at-risk associated to this risk $p$ is defined as:

$$
\mathrm{I} @ \mathrm{R}_{t}^{h}(p)=\mathrm{E}_{i}\left[q_{i t}^{h}(p)\right]
$$

where, as before, $\mathrm{E}_{i}$ denotes the expectation across individual. So $\mathrm{I} @ \mathrm{R}_{t}^{h}(p)$ is thus the average across individuals of quantile, associated to a given risk $p$, in the (subjective) distribution of future inflation. We will consider a risk of $p=5 \%$ and look at both the average of the bottom, $\mathrm{I} @ \mathrm{R}_{t}^{h}(p)$, and top, $\mathrm{I} @ \mathrm{R}_{t}^{h}(1-p)$, of such $5 \%$ individual quantiles.

Two additional characteristics of inflation risks can be derived from these I@R measures. The first one gives a sense of the uncertainty associated to future inflation, i.e. the dispersion in the distribution of future inflation. This is captured by the inter-quantile range which is defined as:

$$
\operatorname{IQR}_{t}^{h}(p)=\mathrm{I} @ R_{t}^{h}(1-p)-\mathrm{I} @ \mathrm{R}_{t}^{h}(p) .
$$


The second one provides an assessment of the balance of the risk to inflation, i.e. the asymmetry of the distribution of future inflation around its central tendency. This asymmetry indicator is given by

$$
\operatorname{ASY}_{t}^{h}(p)=\left[\mathrm{I}_{t}^{h}(1-p)-\mathrm{I}_{\mathrm{R}}^{h}(50)\right]-\left[\mathrm{I}_{t}^{h}(50)-\mathrm{I}_{\mathrm{R}} \mathrm{R}_{t}^{h}(p)\right] .
$$

These last two measures can be related to the robust quantile-based estimator of skewness proposed by Bowley (1920). Using our notations, this is defined as: $\operatorname{RA}_{t}^{h}(p)=$ $\operatorname{ASY}_{t}^{h}(p) / \operatorname{IQR}_{t}^{h}(p)$, and so we have that $\operatorname{ASY}_{t}^{h}(p)=\operatorname{RA}_{t}^{h}(p) \times \operatorname{IQR}_{t}^{h}(p)$. The asymmetry measure that we derive from I@Rs can thus be interpreted as a signed measure of inflation uncertainty.

\section{The MIDAS regression model}

We want to assess whether the information contained in daily financial variables helps predicting quarterly inflation risk indicators. To do so, we have to cope with the problem of explaining a variable of interest with information observed at a higher frequency. In this section, we present the MIDAS regression approach which handles this issue.

Let $y_{t}^{h}$, denote a given survey-based inflation risk indicator associated to the forecasting horizon $h$ and observed at a quarter $t$. In our application, this indicator can be either MPF, $\mathrm{I} @ \mathrm{R}(5 \%), \mathrm{I} @ \mathrm{R}(95 \%), \mathrm{IQR}(5 \%)$, or $\operatorname{ASY}(5 \%)$ and $h$ can be either one or two years. We relate this low-frequency measure to an high-frequency financial variable that is sampled $q$ times faster than the inflation risk dependent variable and that we denote by $x_{t}^{(q)}$. In our application $q$ is equal to 60 , i.e. the number of working days over a quarter.

More specifically, we consider the following autoregressive MIDAS regression model:

$$
y_{t}^{h}=c+\sum_{k=1}^{p} \rho_{k} y_{t-k}^{h}+\beta\left[B\left(L^{1 / q}\right) x_{t}^{(q)}\right]+\varepsilon_{t}
$$

where $B\left(L^{1 / q}\right)=\sum_{j=1}^{j^{\max }} B(j) L^{j / q}$ is a polynomial of order $j^{\max }$ in the $L^{1 / q}$ lag operator defined as $L^{j / q} x_{t}^{(q)}=x_{t-(j / q)}^{(q)}$, which corresponds to the value of $x_{t}^{(q)}$ lagged by $(j / q)$ periods. This regression model has two parts. The first one corresponds to the autoregressive part of the $y_{t}^{h}$ process and captures the information contained at the lowest frequency. The second 
part relates to the MIDAS component of our model and conveys the information contained in financial factors observed at a higher frequency.

In this general specification, the function $B(j)$ is left unconstrained and the coefficients of this polynomial are free parameters. However, such general specification is prone to unprecise estimation. To avoid this over-parametrization problem, one assumes a specific form for the coefficients of the polynomial $B(j ; \theta)$ with $\theta$ being a parsimonious set of parameters.

In this paper, we consider two different forms of the high frequency lag polynomial $B(j ; \theta)$ that are proposed by Ghysels, Sinko, and Valkanov (2007). Both of them can be written as the following weight functions:

$$
B\left(j / j^{\max } ; \theta\right)=\frac{b\left(j / j^{\max } ; \theta\right)}{\sum_{l=1}^{j_{\max }} b\left(l / j^{\max } ; \theta\right)}
$$

The first polynomial specification is the exponential Almon lag polynomial. In this case, $\theta$ is a two dimensional vector of parameters $\theta=\left(\begin{array}{lll}\theta_{1} & \theta_{2}\end{array}\right)^{\prime}$ and the polynomial function is defined by:

$$
b(\omega ; \theta)=e^{\theta_{1} \omega+\theta_{2} \omega^{2}} .
$$

Depending on their combination, the two parameters $\theta_{1}$ and $\theta_{2}$ allow for monotonically decreasing, monotonically increasing, or hump shaped weights of the high frequency variable lags.

The second specification is a constrained form of the beta lag polynomial. It less flexible but more parsimonious than the exponential Almon lag polynomial form above as $\theta$ is a single parameter. The polynomial function is defined by:

$$
b(\omega ; \theta)=(1-\omega)^{\theta-1}
$$

So under this specification, the weights are monotonically decreasing or increasing. ${ }^{1}$

In addition to the form of the MIDAS lag polynomial polynomial function, the model requires specifying a maximum lag in the quarterly observations $p$, as well as a maximum lag for the

\footnotetext{
${ }^{1} \mathrm{~A}$ more general specification of this beta high frequency lag polynomial also involves a two dimensional vector of parameters $\theta=\left(\begin{array}{ll}\theta_{1} & \theta_{2}\end{array}\right)^{\prime}$ and is such that $b(\omega ; \theta)=\omega^{a-1}(1-\omega)^{b-1} \Gamma(a+b) / \Gamma(a) \Gamma(b)$ with $\Gamma(a)=\int_{0}^{\infty} e^{-\omega} \omega^{a-1} d \omega$. This more general case boils down to the restricted form we consider when one sets $a=1$.
} 
daily observation $j^{\max }$. Once this is done, the model can be estimated through non-linear least squares. In the empirical application, we set $j^{\max }=q \times p$ and we choose $p$ that minimizes the RMSE of the estimated model. ${ }^{2}$

\section{Data}

In this section, we describe the quarterly survey data we use in order to measure the inflation risk indicators as well as the daily financial variables we retain to explain them.

\subsection{Inflation risk indicators}

These variables are estimated using the information provided in the ECB Survey of Professional Forecasters (SPF). This survey has been conducted every quarter since 1999Q1. Our sample stops in 2012Q3. It covers around 90 institutions involved in forecasting and operating in the euro area. Each institution is asked to report, among other things, their forecasts for the (year-on-year) euro area HICP inflation rate for fixed horizons of one year and two years ahead of the last available inflation rate observation. Each respondent to the survey provides two types of information: its mean point forecasts and an individual probability distribution over a set of pre-specified intervals for the future inflation. ${ }^{3}$

The first risk measure, the consensus forecast MPF, is directly obtained by taking the average of mean point 1-year (1Y) or 2-year (2Y) ahead inflation forecasts across individuals. The estimation of the I@R, IQR, and ASY indicators relies on the subjective probability distributions provided by the survey. As described in Andrade, Ghysels, and Idier (2012), it first requires to fit continuous generalized beta density distributions over each individual probability distributions about future inflation, using the methodology of Engelberg, Manski, and Williams (2009). For a chosen level of risk, one can then recovers, individual quantiles

\footnotetext{
${ }^{2}$ The MIDAS methodology potentially allows for incorporating several MIDAS polynomials associated with data of frequency other than daily in a single regression. In particular we could incorporate monthly macroeconomic variables into our analysis of the inflation risk measures. Due to the relative short sample period we prefer to focus on single high-frequency regressors MIDAS models. We focus on the mere financial indicators as they have two advantages compared to macroeconomic data: they are available in real-time; and they incorporate both the information revealed in the latest macroeconomic releases as information about the future macroeconomic outlook.

${ }^{3}$ Detailed presentations and discussions of the data can be found in Bowles, Friz, Genre, Kenny, Meyler, and Rautanen (2007).
} 
out of these individual continuous distributions. They are then averaged across individuals to get an estimate of the I@R indicators. We can then and finally construct estimates of the IQR and ASY indicators described in Section 2. ${ }^{4}$ We choose a level of risk equal to $5 \%$. So I@Rs represent the possible levels of inflation that the economy can reach at a one or two year horizon with a probability of $5 \%$ both on the downside and on the upside.

Figure 1 presents the evolution of the five $1 \mathrm{Y}$ horizon inflation risk measures considered. The $\mathrm{MPF}, \mathrm{I} @ \mathrm{R}(5 \%)$ and $\mathrm{I} @ \mathrm{R}(95 \%)$ were very stable in comparison to the shock that affected them in 2008-09. The IQR measure shows that inflation uncertainty was stable before the 2008-09 crisis and reached a new and higher plateau since then. Finally, the ASY measure dropped sharply over 2009 to become negative for a while and slightly positive since mid 2010.

\subsection{Financial market data}

We match the quarterly survey-based risk measures with seven financial indicators that are available at a daily frequency over our sample period. More precisely, a given quarter $t$ is associated with the specific day which is the deadline at which forecasters are asked to answer the survey over this quarter. ${ }^{5}$ This ensures that we include the latest observations of financial variables forecasters have in their information set when they make their predictions, i.e. the observation of the day before answering $t-1 / q$.

This set of variable represents usual factors that contribute to inflation. Oil prices such as the Brent oil price is a natural candidate for explaining the harmonized consumption price index inflation rate the ECB targets. Inflation tend to rise in times of economic booms, when production capacity become strained. Hence, since they are leading indicators of the business cycle, stock market index as the Eurostox $\boldsymbol{5 0}$ and the associated returns can provide valuable information for SPF respondents to early gauge the risk of inflation before its realization. Stock markets also provide a measure of macroeconomic uncertainty, measured through option implied-Eurostoxx 50 volatility index as $\boldsymbol{V} \boldsymbol{S T O X}$. Macroeconomic uncertainty may impact the perception of extreme inflation risks.

Another important factor to assess inflation risk is the expected reaction of the central bank to the current economic outlook. For instance, an expected reversal in the monetary policy

\footnotetext{
${ }^{4}$ See the Appendix A for more details on the estimation procedure.

${ }^{5}$ This information is publicly provided by the ECB.
} 
stance, from accommodative to restrictive, can trigger a reduction of upward inflation risk. In order to take into account these monetary policy expectations, we use the Overnight Index Swap (OIS) rate over a one-month horizon $\boldsymbol{O I S - 1} \boldsymbol{M}$ (the expectation of the next ECB monetary policy decision) and over a one-year horizon $\boldsymbol{O I S - 1} \boldsymbol{Y}$ (the policy rate expected over the medium term). We complement these short and medium term expected interest rates with long-term expectations of economic activity and inflation captured by the slope

of the yield curve. Namely, we consider the difference between the 10-year and 2-year sovereign bond rates Slope-10Y/2Y. We use French bond rates to calculate this term spread. Indeed, it is an intermediary case between German rates and euro area countries which face a sovereign debt crisis at the end of the sample. This choice thus mitigates potential flight-to-quality or liquidity effects that can be at stake over this period of the sample. Finally, we also consider the $\boldsymbol{E} \boldsymbol{U R} / \boldsymbol{U S D}$ exchange rate as a potential factor contributing to perceived inflation through its effect on import prices.

Figure 2 illustrates the potential link between financial market data and the I@R indicators. More precisely, the graph represents the evolution of $\mathrm{I} @ \mathrm{R}(5 \%)$ and $\mathrm{I} @ \mathrm{R}(95 \%)$ with the Brent oil price. A noticeable period is 2006-2009. Oil prices rose very rapidly from the second half of 2006 to the summer of 2007. Over that period, the I@R(95\%) increased while the $\mathrm{I} @ \mathrm{R}(5 \%)$ stayed almost constant. By contrast, oil prices plummeted from September 2007 to September 2008. Over that period, the I@R(95\%) decreased but much less than the the $\mathrm{I} @ \mathrm{R}(5 \%)$ over the same period. The next section further illustrates that inflation risk measures react to different financial variables and that the reaction is not the same whether one considers upward risk or downward risk measures.

\section{Financial data and inflation risks}

In this section, we first describe the specification we retain for the different MIDAS regressions associated to each single financial indicator of inflation risk. We then comment on the non-structural correlations between the inflation risk indicators and the various financial variables that the associated MIDAS regression models enlighten. These correlations are useful, in particular for monetary authorities: they allow to characterize which financial variable is a leading indicator, and with what sign, of the various inflation risk measures that we consider for the analysis. 
All in all, the results underline that the observed changes in several financial indicators do not lead to a simple upward translation of the whole distribution of inflation risks, but to changes in the way the risks are distributed around this central tendency. These results therefore illustrate that looking at the MPF only provides an incomplete assessment of changes in perceived inflation risks.

\subsection{Model selection}

We estimate the MIDAS regression model (3.1) for each of the five inflation risks indicators $y_{t}^{h}-\mathrm{I} @ \mathrm{R}(5 \%), \mathrm{MPF}, \mathrm{I} @ \mathrm{R}(95 \%), \mathrm{IQR}(5 \%)$, and $\mathrm{ASY}(5 \%)$ - and the seven financial variables $x_{t}^{(q)}$ - oil prices (Brent Oil), the euro area stock market index (Eurostoxx 50), the euro area stock market volatility index (VSTOXX), the slope on French bond markets (Slope-10Y/2Y), the 1M EONIA swap rate (OIS-1M), the 1Y EONIA swap rate (OIS-1Y), and the euro-dollar exchange rate (EUR/USD) - presented above.

Financial market data are either transformed in (daily) returns (this is the case for oil prices, equity prices and foreign exchange rates), or in first differences (interest rates and sovereign bonds, volatility index). These transformations ensure that we deal with we stationary data. We estimate the model for both the $1 \mathrm{Y}$ and $2 \mathrm{Y}$ forecast horizons $h$. We consider a range of the auto-regressive lag parameter values of $p=1$ to 4 quarters. The associated range of the MIDAS polynomial maximum lag is thus of $j^{\max }=60$ to 320 days.

Tables 1 and 2 provide the MIDAS regression results obtained when considering a MIDAS exponential polynomial functions for respectively the $1 \mathrm{Y}$ and the $2 \mathrm{Y}$ ahead inflation risks measures. We present the results for a lag parameter equal to $p=1$ which minimizes the RMSE of the majority of the estimated models obtained for the different financial indicators and inflation risk measures. These two tables present the $\mathrm{AR}(1)$ autoregressive coefficient $\rho$, and the effect of a given financial variable (in columns) on a given inflation risk (in rows) $\beta .^{6}$

As a robustness check we estimated the same MIDAS regression model (with the same value of $p=1$ and $j^{\max }=60$ ) but with a beta type MIDAS polynomial rather than an exponential one. The results are presented in Table 3 for the $1 Y$ horizon and in Table 4 for the $2 Y$ horizon. One can check that such a modification in the specification of the MIDAS polynomial leads

\footnotetext{
${ }^{6}$ To save space we do not report the constant $\alpha$ and the MIDAS polynomials parameters $\theta$ in these tables.
} 
to limited differences in terms of the sign and the magnitude of the $\beta$ coefficient carrying the effect of the financial variables on the various inflation risk measures. In the rest of the paper, we focus on such a MIDAS polynomial specification as this specification leads to lower RMSEs. ${ }^{7}$

\subsection{The information content of financial variables on inflation risks}

The following comments are derived from the results provided in Table 1 and Table 2.

Oil prices In line with economic reasoning, oil prices have a significant and positive impact especially on all $1 \mathrm{Y}$ ahead inflation risk indicators. Increase in oil prices are associated with higher average expectation (higher MPF), higher inflation risk quantiles (higher I@R). The I@R do not react the same to an increase in oil prices, with the risk of high inflation outcome (I@R(95\%)) being more sensitive than the risk of low inflation outcome (I@R $(5 \%)$ ). As a consequence, an increase in oil prices leads to higher uncertainty (IQR), and also inflation risks that are tilted towards expectations of high inflation (higher ASY). For the $2 \mathrm{Y}$ inflation, oil prices are only associated with higher risk of extreme positive inflation outcome (I@R(95\%)) hence higher asymmetry. The MPF hardly reacts to oil prices at the $2 \mathrm{Y}$ horizon. Observed changes in oil prices do not lead to a simple upward translation of the whole distribution of inflation risks, but to changes in the ways the risks are distributed around this central tendency with the upside risk of inflation reacting more than the downside one.

Stock market returns and volatility Stock market returns have a positive impact on the MPF on the $1 Y$ and $2 \mathrm{Y}$ horizons: bullish stock markets increase the perceived risk of high inflation associated with a buoyant activity. Stock market returns also have a positive and significant impact on extreme inflation risks (both I@Rs). An increase in stock market returns leads to an upward shift of the whole distribution of future inflation $2 \mathrm{Y}$ ahead as the IQR and ASY indicators are non-significantly affected by such stock market movements.

\footnotetext{
${ }^{7}$ We also looked at the estimation of the various models for an autoregressive lag parameter of $p=3$ rather than $p=1$. This parameter value gives the second-best results in terms of minimizing the RMSE of the different models. The results stay broadly unchanged.
} 
Things are different for the $1 Y$ horizon, with the distribution tending to narrow as stock returns have a negative impact on IQR. Over that shorter horizon, market booms are more certainly associated with an increase in future inflation.

The stock market volatility index (VSTOXX), has a significant negative impact on the MPF and the two I@Rs at both the $1 \mathrm{Y}$ and $2 \mathrm{Y}$ horizons. High stock market uncertainty levels can be perceived as early indicators of a peak in business cycles and hence as raising the probability of future lower inflation rates. Interestingly, recent works like Bloom (2009) show that an increase in stock market uncertainty has recessionary effects and that can be rationalized by a model with irreversible investment. A positive change in stock market volatility increases the asymmetry at the $1 \mathrm{Y}$ horizon and decrease it at the $2 \mathrm{Y}$ one. It also increases the uncertainty at a $2 \mathrm{Y}$ horizons.

Expected monetary policy An expected future monetary policy tightening, be it in $1 \mathrm{M}$ or in $1 \mathrm{Y}$, is positively correlated with a higher level of expected inflation and extreme risk of inflation, $1 \mathrm{Y}$ and $2 \mathrm{Y}$ ahead. The increase in the forecasters' perceived upside risk of inflation is coincident with market expectations that the central bank will increase the policy rate. Expected monetary policy contractions are also associated with an increase in asymmetry at the $1 \mathrm{Y}$ and $2 \mathrm{Y}$ horizons: markets expect monetary policy to be more restrictive in periods when inflation risks are more tilted upward. At the same time, an expected monetary contraction also reduces the uncertainty on inflation expectations $1 Y$ ahead: the signal purported by an expected monetary tightening (through the OIS rate) is sufficiently clear to reduce the uncertainty surrounding future inflation over the short-term. The asymmetry of the distribution of inflation risks is also higher in periods where markets expect an monetary contraction either in $1 \mathrm{M}$ of in $1 \mathrm{Y}$. This is consistent with the findings of Andrade, Ghysels, and Idier (2012) who emphasize that monetary authorities react to the asymmetry of the inflation risks as such.

The yield curve According to our estimation results, an increase in the slope of the yield curve has a strong negative impact on the MPF, and lower inflation risk on both the $\mathrm{I} @ \mathrm{R}(95 \%)$ and $\mathrm{I} @ \mathrm{R}(5 \%)$ at both the $1 \mathrm{Y}$ and $2 \mathrm{Y}$ horizons. Moreover, a positive change in the yield curve lowers the asymmetry at both the $1 \mathrm{Y}$ and $2 \mathrm{Y}$ horizons, and contributes significantly to greater inflation uncertainty at the $1 Y$ horizon. An increase in the slope of the yield curve is usually interpreted as an indicator of a contracting economy (i.e. the 
short end of the curve decreases while the long-end stays approximately constant) which lowers inflation pressures and increases the downward risks to inflation more compared to the upward risks.

Exchange rate According to our results exchange rate fluctuations only have a weak negative impact on IQR and a positive impact on I@R(5\%) at the $1 Y$ horizon. This evidence of a weak link between exchange rate fluctuations and the short-term inflation risk measures can be related to the well-known incomplete pass-through of exchange rate fluctuations to import prices (see for instance Gopinath and Rigobon (2008) for recent evidence). At a longer horizon of $2 \mathrm{Y}$, an appreciation of the euro compared to the USD leads to an increase in the MPF. This is at odds with the deflationary pressures that cheaper imported inputs would then induce. A possible interpretation of this result is that the exchange rate reacts to interest rate differentials between the euro area and the US. So an appreciation of the euro is related to current (or recent) monetary contractions in the euro area, hence a lower expected inflation rate. ${ }^{8}$ No matter the causality, one can also note that an appreciation of the euro against the dollar is associated with a lower uncertainty about future inflation.

\section{Forecasting performances}

In this section we assess whether, and by how much, the daily financial variables improve the forecasting of the quarterly inflation risk measures upon simple autoregressive models which do not incorporate this high frequency data information.

\subsection{Approach}

We run two different exercises. The first one is conducted using the estimation of the MIDAS regression model (3.1) over the whole sample of data, that is up to date $T=2012 \mathrm{Q} 3$. More precisely, we compare the realizations of inflation risk measures $y_{t}^{h}$ to the in-sample end-of-

\footnotetext{
${ }^{8}$ Identifying an effect of exchange rate fluctuations keeping monetary policy in the euro-area constant would require to estimate a model with at least two financial indicators. While this is feasible in theory, extending the methodology to a set of multivariate high frequency regressors would be questionable in our particular application. Indeed the estimation becomes uncertain when the available sample is relatively limited as this is the case in the present study.
} 
period forecasts:

$$
\widehat{y}_{t \mid T, x}^{h}=c+\sum_{k=1}^{p} \widehat{\rho}_{k \mid T} y_{t-k}^{h}+\widehat{\beta}_{T}\left[\widehat{B}_{T}\left(L^{1 / q}\right) x_{t}^{(q)}\right] .
$$

These predictions of $y_{t}^{h}$ thus use the information content of the past observed values $y_{t-1}^{h}, \ldots, y_{t-p}^{h}$ and the financial indicators observed up to the day before date $t$. For each financial indicator $x$, we compute the series of forecast errors, $e_{t \mid T, x}^{h}=y_{t}^{h}-\widehat{y}_{t \mid T, x}^{h}$ and the associated root mean squared error (RMSE). We compare the precision of these forecasts with the one of forecasts obtained from an equivalent autoregressive model that does not include the financial variable, namely

$$
\widehat{y}_{t \mid T, \text { ar }}^{h}=c+\sum_{k=1}^{p} \widehat{\rho}_{k \mid T} y_{t-k}^{h}
$$

More specifically, we compute the RMSE of this simpler model and compare it with the one of the various MIDAS regressions.

The second exercise also considers forecasting end-of-period inflation risk measures but in real-time. More precisely, we first initialize the estimation the MIDAS regression model (3.1) on a 1999Q2 to 2006Q3 sample, that is using 30 data points. Then, for each date $t>$ 2006Q3, we re-estimate the model recursively using an expanding window up to $t=T-1=$ 2012Q2. We get out-of-sample end-of-period forecasts as:

$$
\widehat{y}_{t \mid t-1, x}^{h}=c+\sum_{k=1}^{p} \widehat{\rho}_{k \mid t-1} y_{t-k}^{h}+\widehat{\beta}_{t-1}\left[\widehat{B}_{t-1}\left(L^{1 / q}\right) x_{t}^{(q)}\right] .
$$

This leaves us with a sample of 25 estimations that we can compare to realizations $y_{t}^{h}$.

In addition to these out-of-sample forecasts obtained from single financial indicators MIDAS regressions, we also compute the forecasts derived from an average of the single predictor models. ${ }^{9} \quad$ More specifically, letting $\widehat{y}_{t \mid t-1, x=m}^{h}$ be the prediction derived from the MIDAS regression associated to the financial indicator $x=m$, with $m=1, \ldots, M$, with $M$ be the

\footnotetext{
${ }^{9} \mathrm{As}$ is well known, model averaging techniques often improve the precision of forecasts compare to the individual models. Banerjee, Marcellino, and Masten (2005) provide an illustration for inflation and GDP forecasts in the euro-area. See Clemen (1989) or Timmermann (2006) for surveys on model averaging.
} 
number of financial indicators considered, we compute:

$$
\widehat{y}_{t \mid t-1, \mathrm{avg}}^{h}=\sum_{m=1}^{M} w_{m, t-1} \widehat{y}_{t \mid t-1, x=m}^{h}
$$

We consider two model averaging schemes: a simple average for which $w_{m, t-1}=\frac{1}{M}$ for all $m=1, \ldots, M$ and $t=1, \ldots, T-1$; and a recursive optimal averaging scheme for which:

$$
w_{m, t-1}=\frac{\exp \left(-\frac{1}{2} \mathrm{BIC}_{m, t-1}\right)}{\sum_{l=1}^{M} \exp \left(-\frac{1}{2} \mathrm{BIC}_{l, t-1}\right)}
$$

where $\mathrm{BIC}_{m, t-1}$ is the Bayesian information criteria of model $m$ estimated up to date $t$. This is in line with Buckland, Burnham, and Augustin (1997) who use information criteria to defining the weights.

We compare the forecasting performances of this set of individual models and model averages with the ones obtained from the following recursive estimates of the $\operatorname{AR}(p)$ model

$$
\widehat{y}_{t \mid t-1, \text { ar }}^{h}=c+\sum_{k=1}^{p} \widehat{\rho}_{k \mid t-1} y_{t-k}^{h} .
$$

We also compare these real-time forecasts with the one obtained from a simple random walk (RW) model:

$$
\widehat{y}_{t \mid t-1, \mathrm{rw}}^{h}=y_{t-1}^{h} \text {. }
$$

As is well-known, for persistent processes, this model is hard to beat out-of-sample as it does not suffer from parameter estimation variability. Models are compared on the basis of their RMSE statistics.

\subsection{Results}

Table 5 gives the RMSE associated to the in-sample end-of-period forecasts of the MIDAS regressions associated to the various financial indicators for the different inflation risk measures. We compare these forecasting performances with the ones of a simple autoregressive model and a random walk.

The first striking result that emerges from this table is that the high frequency financial 
variables improve the fit of the data compared to a simple autoregressive models, for all inflation risk measures and all financial variables considered. Considering the uniform model averaging of MIDAS regressions against the simple AR(1) model, financial indicators improve the RMSE by $32.7 \%$ for the I@R(5\%), 23.9\% for the MPF, $23.7 \%$ for the $\mathrm{I} @ \mathrm{R}(95 \%), 16.4 \%$ for the IQR, and $15.4 \%$ for ASY. This result also holds at $2 \mathrm{Y}$ horizon for which simple model averaging improves the RMSE compared to a simple AR(1) by respectively by $29.3 \%$ for the $\mathrm{I} @ \mathrm{R}(5 \%), 26.2 \%$ for the MPF, $19.3 \%$ for the I@R(95\%), 41.3\% for IQR, and $24.6 \%$ for the IQR, considering strategy. Model averages also outperform the RW.

The second important result is that, depending on the inflation risk measure and the horizon considered, it is not always the same financial variable that gives the best model fit improvement compared to the simple AR(1). At the $1 \mathrm{Y}$ horizon, the Slope- $10 \mathrm{Y} / 2 \mathrm{Y}$ is the most informative indicator for the $\mathrm{I} @ \mathrm{R}(5 \%)$ and the MPF. Brent oil prices is the best predictor for the I@R(95\%) and the ASY. Finally, the VSTOXX is the financial variable that is the most informative for the IQR. At the $2 \mathrm{Y}$ horizon, the expected policy rate (at either $1 \mathrm{M}$ or $1 \mathrm{Y})$ is the most informative indicator for the $\mathrm{I} @ \mathrm{R}(5 \%)$, the MPF, the $\mathrm{I} @ \mathrm{R}(95 \%)$ and the IQR, while oil prices are the most informative for the ASY measures

The result that high frequency financial variables improve the precision of forecasts also holds in real-time as shown in Table 6. This table presents the RMSFE associated to the out-of-sample end-of-period forecasts of the different single indicator MIDAS regressions, of two model averaging methods (uniform and BIC weighted) based on the these single indicator models, and of a simple AR(1) model and a RW model. At the $1 Y$ horizon, forecast performances obtained with the uniform model averaging technique are $14.8 \%$ better compared to an AR(1) model for the $\mathrm{I} @ \mathrm{R}(5 \%), 10.8 \%$ for the MPF, 6.7\% for the $\mathrm{I} @ \mathrm{R}(95 \%)$ and $9.5 \%$ for the ASY. Model averaging also does better than the RW for these four risk measures. At the $2 \mathrm{Y}$ horizon, the simple average of models only (slightly) improves the forecast of the ASY measures. In the case of the horizons and measures for which the model averages do not outperfom the $\operatorname{AR}(1)$, there is always at least one single financial indicator that does. As for the in-sample exercise, this is not always the same variable that is the most informative for out-of-sample forecasts. In 7 cases out of the 10 studied, expected monetary policy provides the strongest forecast precision improvement.

All in all, we conclude from our forecast performance comparisons that daily financial indicators bring supplementary information on what drives the evolution of the inflation risk measures. Moreover, among the set of indicators that we studied, the monetary policy 
stance that markets expect (either OIS-1M or OIS-1Y) stand out as the indicators that improves forecasts the most significantly.

\section{Conclusion}

Inflation risks are key dimensions to understand the action of central banks. These latter are particularly eager to understand and monitor their evolution and determinants. Survey based inflation expectations, and especially individual probability distribution, are useful low frequency (typically quarterly) indicators of future inflation risks. However, there has been no attempt so far for identifying what may drive the responses of the forecasters, and especially what economic scenarios respondents may have in mind for inflation at the date of the survey.

Financial market information, being real-time and forward-looking, is used in this spirit to rationalize the information set of forecasters relying on MIDAS regressions to overcome the frequency mismatch of the data. We find that financial data do not have the same impact

on these different indicators. Relying on the mere and usual average of mean point forecasts thus leads to an incomplete analysis of inflation risks as it aggregates economic mechanisms such that the role of unbalanced upside and downside risks of inflation, or the increase in uncertainty. The results also outline that market-based expectations about future monetary policy is an important driver for most of the inflation risk measures.

We emphasize that financial market data help predicting various measures of inflation risks, including the usual average mean point forecast, but also distribution based indicators of the uncertainty in future inflation rates, as of the asymmetry in the distribution of inflation risks. As a consequence, daily financial indicators can be used to estimate inflation risks at a higher frequency than quarterly and to provide monetary authorities with an evaluation of these risks within two subsequent releases of the survey. 


\section{References}

Andrade, P., E. Ghysels, and J. Idier, 2012, Tails of Inflation Forecasts and Tales of Monetary Policy, Banque de France Working Paper 407.

Andrade, P., and H. Le Bihan, 2010, Inattentive Professional Forecasters, Banque de France Working Paper 307.

Ang, A., G. Bekaert, and M. Wei, 2007, Do Macro Variables, Asset Markets, or Surveys Forecast Inflation Better?, Journal of Monetary Economics 54, 1163-1212.

Banerjee, A., M. Marcellino, and I. Masten, 2005, Leading Indicators for Euro-area Inflation and GDP Growth, Oxford Bulletin of Economics and Statistics 67, 785-813.

Bloom, N., 2009, The impact of uncertainty shocks, Econometrica 77, 623-685.

Bowles, C., R. Friz, V. Genre, G. Kenny, A. Meyler, and T. Rautanen, 2007, The ECB Survey of Professional Forecasters (SPF): A Review After Eight Years' Experience, ECB Occasional Paper No. 59.

Bowley, A., 1920, Elements of Statistics (New York: Charles Scribner's Sons).

Bryan, M., S.G. Cecchetti, and R.L. Wiggins II, 1997, Efficient Inflation Estimations, NBER Working Paper 6183.

Buckland, S. T., K. P. Burnham, and N. H. Augustin, 1997, Model Selection: An Integral Part of Inference, Biometrics 53(2), 603-618.

Cecchetti, S.G., 2008, Measuring the Macroeconomic Risks Posed by Asset Price Booms, in J.Y. Campbell, ed.: Asset Prices and Monetary Policy pp. 9-43. NBER.

Christensen, R., J. Lopez, and G. Rudebusch, 2011, Extracting Deflation Probability Forecasts from Treasury Yields, FRBSF Working Paper 2011-10.

Clemen, R., 1989, Combining Forecasts: A Review and Annotated Bibliography, International Journal of Forecasting 5, 559-583.

Coibion, O., and Y. Gorodnichenko, 2012, What Can Survey Forecasts Tell Us about Information Rigidities?, Journal of Political Economy 120, 116-159. 
Engelberg, J., C.F. Manski, and J. Williams, 2009, Comparing the Point Predictions and Subjective Probability Distributions of Professional Forecasters, Journal of Business and Economic Statistics 27, 30-41.

Engle, R., 1982, Autoregressive Conditional Heteroscedasticity with Estimates of Variance of United Kingdom Inflation, Econometrica 50, 987-1008.

Galvao, A.B., and M.P. Clements, 2008, Macroeconomic Forecasting with Mixed Frequency Data: Forecasting Output Growth in the United States, Journal of Business and Economics Statistics 26, 546-554.

Garcia, J.A., and A. Manzanares, 2007, What Can Probability Forecasts Tell Us About Inflation Risk?, ECB Working Paper 825.

Ghysels, E., P. Santa-Clara, and R. Valkanov, 2002, The MIDAS touch: Mixed Data Sampling Regression Models, mimeo, UNC and UCLA.

Ghysels, E., A. Sinko, and R. Valkanov, 2007, MIDAS Regressions: Further Results and New Directions, Econometric Reviews 26, 53-90.

Ghysels, E., and J.H. Wright, 2009, Forecasting Professional Forecasters, Journal of Business and Economic Statistics 27, 504-516.

Gopinath, G., and R. Rigobon, 2008, Sticky Borders, Quarterly Journal of Economics 123(2), $531-575$.

Kilian, L., and S. Manganelli, 2008, The Central Banker as a Risk Manager: Estimating the Federal Reserve's Preferences under Greenspan, Journal of Money, Credit and Banking 40, 1103-1129.

Marcellino, M., and C. Schumacher, 2008, Factor-MIDAS for Now- and Forecasting with Ragged-edge Data: A Model Comparison for German GDP, Oxford Bulletin of Economics and Statistics 72, 518-550.

Monteforte, L., and G. Moretti, 2010, Real-Time Forecasts of Inflation: the Role of Financial Variables, Banca d'Italia Working Paper 767.

Stock, J., and M. Watson, 2003, Forecasting Output and Inflation: The Role of Asset Prices, Journal of Economic Literature 41, 788-829. 
Timmermann, A., 2006, Forecast Combinations, in G. Elliott, C.W.J. Granger, and A. Timmermann, ed.: Handbook of Economic Forecasting pp. 135-196. Amsterdam: North Holland. 


\section{A Estimation of I@R}

We follow the methodology of Engelberg, Manski, and Williams (2009) who consider matching generalized beta distributions to the individual discrete histograms. More precisely, one distinguishes three cases, depending on the number of classes (non-zero probability histogram bins) used by a respondent.

1. If a forecaster uses only one class by responding $100 \%$ probability for a given inflation interval from $l$ to $u$, the probability distribution function is assumed to be an isocele triangle with a peak of the distribution attained for $(l+u) / 2$.

2. If a forecaster uses two adjacent intervals $\left(l_{1} ; u_{1}\right]$ and $\left(l_{2} ; u_{2}\right]$, with $u_{1}=l_{2}$, one also postulates an isocele triangle shaped distribution such that:

- if $p_{1}>p_{2}$, i.e. the probability assigned to the first interval is greater than the probability assigned to the second one, the isocele triangle has a basis $\left[l_{1} ; x\right]$ where $x \in\left(u_{1} ; u_{2}\right]$. The use of Thales theorem (see Engelberg, Manski, and Williams (2009) for the details) allows to determine $x$.

- if conversely, $p_{1}<p_{2}$, the isocele triangle has a basis $\left[x ; u_{2}\right]$ where $x \in\left[l_{1} ; u_{1}\right]$.

3. if a forecaster uses three or more intervals, each individual distribution is fitted with a generalized beta distribution whose cumulative distribution function $F$ is:

$$
F\left(x ; a, b, L_{i t}, U_{i t}\right)= \begin{cases}0 & \text { if } x \leq L_{i t} \\ \frac{1}{B(a, b)} \int_{L_{i t}}^{x} \frac{\left(z-L_{i t}\right)^{a-1}\left(U_{i t}-z\right)^{b-1}}{\left(U_{i t}-L_{i t}\right)^{a+b-1}} d z & \text { if } \quad L_{i t}<x<U_{i t} \\ 1 & \text { if } x \geq U_{i t}\end{cases}
$$

where $a$ and $b$ are the two parameters defining the beta distribution, $B(a, b)=\frac{\Gamma(a) \Gamma(b)}{\Gamma(a+b)}$, with $\Gamma(b)=\int_{0}^{\infty} z^{(a-1)} e^{-z} d z$, and where $L_{i t}$ and $U_{i t}$ are respectively the lower and upper bounds of the support used by the respondent $i$ at date $t$.

To estimate the two parameters $(a, b)$ characterizing the generalized beta distribution, one minimizes the squared distance between the discretized version of the empirical CDF and the continuous CDF for each date $t$ and forecasters $i$ as follows:

$$
\min _{a>1, b>1} \sum_{j=1}^{J_{t}}\left[F_{i t}^{h}\left(u_{j} ; a, b, L_{i t}, U_{i t}\right)-\sum_{k=1}^{j} p_{i t}^{h}(k)\right]^{2},
$$


with $J_{t}$ the number of class available in the survey at date $t$ and with $p_{i t}^{h}(k)$ the probability assigned by forecaster $i$ to the interval $\left(l_{k} ; u_{k}\right]$. Remark that the cumulative of the beta is evaluated at the upper bonds of the intervals. The restriction $a>1, b>1$ implies that the beta distribution is unimodal. The extreme upper and lower intervals in the SPF questionnaire are open-ended. An important step in the procedure is to close these open intervals with arbitrary chosen lower and upper values for inflation. We follow Engelberg, Manski, and Williams (2009) (and the common practice in this literature) by assuming that the two extreme intervals have a width of twice the size of the intermediate ones.

We denote $\hat{a}_{i t}^{h}$ and $\hat{b}_{i t}^{h}$ the estimated parameters of the beta distribution for forecaster $i$ and date $t$ and $\widehat{F}_{i t}^{h}=F\left(x ; \hat{a}_{i t}^{h}, \hat{b}_{i t}^{h}, L_{i t}, U_{i t}\right)$ the corresponding generalized beta distribution. The individual's $\hat{q}_{i t}^{h}(p)$ is the quantile of the continuous distribution $\widehat{F}_{i t}^{h}$ at the probability threshold $p$, namely:

$$
\hat{q}_{i t}^{h}(p)=\left(\widehat{F}_{i t}^{h}\right)^{-1}(p) .
$$

Therefore $\widehat{\mathrm{I}}_{t}^{h}(p)$ is the cross-sectional average across survey respondents of $\hat{q}_{i t}(p)$. Likewise, the empirical $\widehat{\mathrm{QR}}_{t}^{h}(p)$ and $\widehat{\mathrm{ASY}}_{t}^{h}(p)$ measures are obtained using the cross-sectional average across survey respondents of $\hat{q}_{i t}(p), \hat{q}_{i t}(1-p)$ and $\hat{q}_{i t}(.50)$ as specified in Section 2. Note that in the paper we drop the hats and simply refer to $\operatorname{I}_{t}^{h}(p), \operatorname{IQR}_{t}^{h}(p)$, and $\operatorname{ASY}_{t}^{h}(p)$ with the understanding that they are estimated quantities. 


\begin{tabular}{|c|c|c|c|c|c|c|c|c|}
\hline & & Oil Prices & Eurostoxx50 & VSTOXX & OIS-1M & OIS-1Y & Slope-10Y/2Y & EUR/USD \\
\hline \multirow[t]{4}{*}{$\mathrm{I} @ \mathrm{R}(5 \%)$} & $\rho$ & $0.853^{* * *}$ & $0.937 * * *$ & $0.917^{* * *}$ & $0.861^{* * *}$ & $0.893^{* * *}$ & $0.845^{* * *}$ & $0.869^{* * *}$ \\
\hline & & [18.062] & [18.719] & {$[18.632]$} & {$[15.676]$} & [18.929] & [19.954] & [18.481] \\
\hline & $\beta$ & $0.34^{* * *}$ & $1.047^{* * *}$ & $-0.076^{* * *}$ & $7.39 * * *$ & $8.34^{* * *}$ & $-15.796^{* * *}$ & $0.465^{*}$ \\
\hline & & {$[3.07]$} & {$[2.921]$} & {$[-5.73]$} & {$[7.382]$} & {$[3.253]$} & {$[-5.7]$} & {$[1.747]$} \\
\hline \multirow[t]{4}{*}{$\mathrm{MPF}$} & $\rho$ & $0.791^{* * *}$ & $0.869^{* * *}$ & $0.892^{* * *}$ & $0.804^{* * *}$ & $0.825^{* * *}$ & $0.805^{* * *}$ & $0.766^{* * *}$ \\
\hline & & [13.37] & [13.421] & {$[14.827]$} & {$[12.71]$} & [15.619] & {$[13.167]$} & {$[9.886]$} \\
\hline & $\beta$ & $0.261^{* * *}$ & $0.798 * * *$ & $-0.06^{* * *}$ & $6.249^{* * *}$ & $6.948^{* * *}$ & $-13.02 * * *$ & 0.922 \\
\hline & & {$[3.348]$} & {$[2.779]$} & {$[-3.703]$} & [6.155] & {$[4.252]$} & {$[-6.174]$} & {$[0.784]$} \\
\hline \multirow[t]{4}{*}{$\mathrm{I} @ \mathrm{R}(95 \%)$} & $\rho$ & $0.773^{* * *}$ & $0.835^{* * *}$ & $0.783^{* * *}$ & $0.76^{* * *}$ & $0.791^{* * *}$ & $0.775^{* * *}$ & $0.715^{* * *}$ \\
\hline & & [10.089] & [11.911] & {$[10.123]$} & {$[9.49]$} & {$[10.952]$} & {$[7.217]$} & {$[8.554]$} \\
\hline & $\beta$ & $0.302^{* * *}$ & $0.814^{* * *}$ & -0.181 & $6.016^{* * *}$ & $6.852^{* * *}$ & $-11.901^{* * *}$ & 1.299 \\
\hline & & {$[4.144]$} & {$[2.702]$} & {$[-1.637]$} & {$[5.553]$} & {$[3.912]$} & {$[-4.521]$} & {$[1.514]$} \\
\hline \multirow[t]{4}{*}{ IQR } & $\rho$ & $0.943^{* * *}$ & $0.961^{* * *}$ & $0.981^{* * *}$ & $0.952^{* * *}$ & $0.952^{* * *}$ & $0.961^{* * *}$ & $0.931^{* * *}$ \\
\hline & & [19.294] & {$[26.208]$} & [31.103] & {$[23.064]$} & [21.647] & [22.095] & [24.123] \\
\hline & $\beta$ & $0.036^{* *}$ & $-0.103^{* * *}$ & $0.03^{* * *}$ & $-2.473^{* * *}$ & $-2.563^{* *}$ & $4.445^{* * *}$ & $-0.109^{* *}$ \\
\hline & & [2.033] & {$[-2.625]$} & {$[5.142]$} & {$[-2.383]$} & {$[-2.167]$} & [2.896] & {$[-2.153]$} \\
\hline \multirow[t]{4}{*}{ ASY } & $\rho$ & $0.652^{* * *}$ & $0.679 * * *$ & $0.618^{* * *}$ & $0.592^{* * *}$ & $0.625^{* * *}$ & $0.596^{* * *}$ & $0.61^{* * *}$ \\
\hline & & [8.177] & {$[6.308]$} & [5.789] & [8.314] & {$[7.464]$} & [8.781] & {$[6.624]$} \\
\hline & $\beta$ & $0.18^{* * *}$ & 0.216 & $0.012^{* * *}$ & $1.881^{* * *}$ & 1.881 & $-2.336^{* * *}$ & 0.42 \\
\hline & & [2.496] & {$[1.597]$} & [4.419] & {$[2.322]$} & {$[1.358]$} & {$[-2.688]$} & {$[1.299]$} \\
\hline
\end{tabular}

Table 1: Quarterly inflation risks and daily financial variables

The Table presents the estimation results of the autoregressive MIDAS model (3.1) for the various 1Y ahead quarterly inflation risk measures and daily financial indicators. The specification involves an $\operatorname{AR}(1)$ autoregressive term $\left(p=1\right.$ quarter and $j^{\max }=60$ days) and an exponential Almon lag MIDAS polynomial. The model is estimated by NLLS. For brevity we only present the estimates of the (first-order) autoregressive parameter $\rho$, and the loading of the MIDAS polynomials $\beta$. Terms in brackets are the associated (HAC corrected) $t$-stats. Stars indicate significance at the $2.5 \%(* * *), 5 \%(* *)$, and $10 \%\left(^{*}\right)$ levels (one-sided test). 


\begin{tabular}{|c|c|c|c|c|c|c|c|c|}
\hline & & Oil Prices & Eurostoxx50 & VSTOXX & OIS-1M & OIS-1Y & Slope-10Y/2Y & EUR/USD \\
\hline \multirow[t]{4}{*}{$\mathrm{I} @ \mathrm{R}(5 \%)$} & $\rho$ & $0.886^{* * *}$ & $0.922^{* * *}$ & $0.957^{* * *}$ & $0.878^{* * *}$ & $0.903^{* * *}$ & $0.861^{* * *}$ & $0.921^{* * *}$ \\
\hline & & {$[16.258]$} & [16.646] & {$[20.152]$} & [19.507] & {$[20.828]$} & [17.869] & {$[22.789]$} \\
\hline & $\beta$ & 0.184 & $0.635^{*}$ & $-0.232^{* * *}$ & $2.897 * * *$ & $5.681^{* * *}$ & $-9.377^{* * *}$ & 0.329 \\
\hline & & {$[1.288]$} & [1.79] & {$[-3.351]$} & {$[3.174]$} & [5.935] & {$[-3.34]$} & [1.308] \\
\hline \multirow[t]{4}{*}{$\mathrm{MPF}$} & $\rho$ & $0.787^{* * *}$ & $0.868^{* * *}$ & $0.915^{* * *}$ & $0.844^{* * *}$ & $0.875^{* * *}$ & $0.826^{* * *}$ & $0.746^{* * *}$ \\
\hline & & [11.418] & [13.184] & [14.929] & [13.06] & [14.713] & {$[14.508]$} & [10.153] \\
\hline & $\beta$ & 0.179 & $0.349^{* *}$ & $-0.029 * * *$ & $2.764^{* * *}$ & $2.175^{* * *}$ & $-4.669 * * *$ & 0.582 \\
\hline & & [1.041] & [2.013] & {$[-4.498]$} & {$[3.428]$} & {$[3.777]$} & {$[-2.553]$} & {$[0.885]$} \\
\hline \multirow[t]{4}{*}{$\mathrm{I} @ \mathrm{R}(95 \%)$} & $\rho$ & $0.829^{* * *}$ & $0.851^{* * *}$ & $0.844^{* * *}$ & $0.834^{* * *}$ & $0.85^{* * *}$ & $0.845^{* * *}$ & $0.77^{* * *}$ \\
\hline & & [12.383] & {$[13.574]$} & [14.385] & [13.628] & {$[11.506]$} & {$[12.427]$} & {$[11.288]$} \\
\hline & $\beta$ & $0.115^{* * *}$ & $0.338^{* * *}$ & $-0.124^{* * *}$ & $2.496^{*}$ & $2.353^{*}$ & $-4.562^{* *}$ & 0.738 \\
\hline & & [2.698] & [2.369] & {$[-2.484]$} & {$[1.792]$} & {$[1.668]$} & {$[-2.104]$} & {$[1.581]$} \\
\hline \multirow[t]{4}{*}{ IQR } & $\rho$ & $0.922^{* * *}$ & $0.941^{* * *}$ & $0.946^{* * *}$ & $0.966^{* * *}$ & $0.904^{* * *}$ & $0.926^{* * *}$ & $0.947 * * *$ \\
\hline & & [14.366] & [16.345] & [16.09] & [15.01] & {$[15.472]$} & [14.072] & [16.375] \\
\hline & $\beta$ & -0.037 & -0.163 & -0.035 & 3.711 & 2.265 & -5.695 & $-0.206^{* *}$ \\
\hline & & {$[-0.931]$} & {$[-1.033]$} & {$[-0.864]$} & [1.408] & [1.46] & {$[-1.604]$} & {$[-2.192]$} \\
\hline \multirow[t]{4}{*}{$\mathrm{ASY}$} & $\rho$ & $0.66^{* * *}$ & $0.627^{* * *}$ & $0.712^{* * *}$ & $0.486^{* * *}$ & $0.532^{* * *}$ & $0.505^{* * *}$ & $0.539 * * *$ \\
\hline & & [7.164] & [6.5] & {$[7.641]$} & {$[5.318]$} & [7.04] & {$[5.856]$} & [5.554] \\
\hline & $\beta$ & $0.131^{* * *}$ & 0.196 & $-0.149 * * *$ & $3.984^{* * *}$ & $3.361^{* * *}$ & $-6.889 * * *$ & 0.334 \\
\hline & & {$[2.651]$} & {$[1.201]$} & {$[-3.282]$} & [4.215] & {$[3.392]$} & {$[-4.397]$} & {$[0.489]$} \\
\hline
\end{tabular}

Table 2: Quarterly inflation risks and daily financial variables

The Table presents the estimation results of the autoregressive MIDAS model (3.1) for the various 2Y ahead quarterly inflation risk measures and daily financial indicators. The specification involves an $\operatorname{AR}(1)$ autoregressive term ( $p=1$ quarter and $j^{\max }=60$ days) and an exponential Almon lag MIDAS polynomial. The model is estimated by NLLS. For brevity we only present the estimates of the (first-order) autoregressive parameter $\rho$, and the loading of the MIDAS polynomials $\beta$. Terms in brackets are the associated (HAC corrected) $t$-stats. Stars indicate significance at the $2.5 \%(* * *), 5 \%(* *)$, and $10 \%\left(^{*}\right)$ levels (one-sided test). 


\begin{tabular}{|c|c|c|c|c|c|c|c|c|}
\hline & & Oil Prices & Eurostoxx50 & VSTOXX & OIS-1M & OIS-1Y & Slope-10Y/2Y & EUR/USD \\
\hline \multirow[t]{4}{*}{$\mathrm{I} @ \mathrm{R}(5 \%)$} & $\rho$ & $0.864^{* * *}$ & $0.93^{* * *}$ & $0.933^{* * *}$ & $0.864^{* * *}$ & $0.863^{* * *}$ & $0.856^{* * *}$ & $0.865^{* * *}$ \\
\hline & & {$[17.473]$} & {$[18.215]$} & {$[18.872]$} & {$[19.076]$} & [18.994] & {$[20.67]$} & [16.694] \\
\hline & $\beta$ & $0.427^{*}$ & $1.07^{* * *}$ & $-0.339 * * *$ & $7.973^{* * *}$ & $8.8^{* * *}$ & $-14.472^{* * *}$ & 0.531 \\
\hline & & {$[1.932]$} & {$[3.123]$} & {$[-2.513]$} & {$[4.324]$} & {$[3.733]$} & {$[-4.366]$} & [0.739] \\
\hline \multirow[t]{4}{*}{$\mathrm{MPF}$} & $\rho$ & $0.798^{* * *}$ & $0.864^{* * *}$ & $0.835^{* * *}$ & $0.803^{* * *}$ & $0.79^{* * *}$ & $0.804^{* * *}$ & $0.776^{* * *}$ \\
\hline & & [13.488] & {$[13.276]$} & {$[12.334]$} & {$[12.387]$} & {$[12.218]$} & [14.296] & {$[10.082]$} \\
\hline & $\beta$ & $0.317^{* * *}$ & $0.818^{* * *}$ & $-0.194^{*}$ & $6.332^{* * *}$ & $7.127 * * *$ & $-11.706^{* * *}$ & 0.497 \\
\hline & & {$[2.325]$} & {$[2.914]$} & {$[-1.786]$} & [6.631] & [3.908] & {$[-5.059]$} & {$[0.838]$} \\
\hline \multirow[t]{4}{*}{$\mathrm{I} @ \mathrm{R}(95 \%)$} & $\rho$ & $0.781^{* * *}$ & $0.821^{* * *}$ & $0.774^{* * *}$ & $0.751^{* * *}$ & $0.762^{* * *}$ & $0.77^{* * *}$ & $0.73^{* * *}$ \\
\hline & & [10.6] & [11.665] & {$[10.229]$} & [9.392] & {$[9.252]$} & [10.775] & {$[9.382]$} \\
\hline & $\beta$ & $0.392^{* * *}$ & $0.787 * * *$ & -0.166 & $6.522 * * *$ & $6.657 * * *$ & $-10.648^{* * *}$ & $1.28^{*}$ \\
\hline & & {$[2.438]$} & [2.603] & {$[-1.305]$} & {$[5.142]$} & [3.265] & {$[-3.819]$} & {$[1.794]$} \\
\hline \multirow[t]{4}{*}{ IQR } & $\rho$ & $0.966^{* * *}$ & $0.961^{* * *}$ & $0.979^{* * *}$ & $0.962^{* * *}$ & $0.955^{* * *}$ & $0.959 * * *$ & $0.97^{* * *}$ \\
\hline & & [21.398] & [26.181] & {$[25.458]$} & [23.179] & [21.27] & {$[23.422]$} & {$[27.412]$} \\
\hline & $\beta$ & -0.05 & $-0.101^{* * *}$ & $0.084^{* * *}$ & $-2.288^{* * *}$ & $-2.591^{* * *}$ & $4.423^{* * *}$ & 0.407 \\
\hline & & {$[-0.49]$} & {$[-2.662]$} & [2.423] & {$[-2.414]$} & {$[-2.315]$} & [2.223] & [0.988] \\
\hline \multirow[t]{4}{*}{$\mathrm{ASY}$} & $\rho$ & $0.658^{* * *}$ & $0.65^{* * *}$ & $0.656^{* * *}$ & $0.588^{* * *}$ & $0.63^{* * *}$ & $0.573^{* * *}$ & $0.629 * * *$ \\
\hline & & [8.365] & [6.812] & [6.454] & [8.213] & [8.094] & {$[7.576]$} & {$[7.672]$} \\
\hline & $\beta$ & $0.182^{* * *}$ & 0.197 & -0.066 & $2.196^{*}$ & 1.675 & -2.698 & 0.4 \\
\hline & & {$[2.556]$} & {$[1.274]$} & {$[-0.98]$} & {$[1.677]$} & {$[1.244]$} & {$[-1.307]$} & [1.31] \\
\hline
\end{tabular}

Table 3: Quarterly inflation risks and daily financial variables

The Table presents the estimation results of the autoregressive MIDAS model (3.1) for the various 1Y ahead quarterly inflation risk measures and daily financial indicators. The specification involves an $\operatorname{AR}(1)$ autoregressive term $\left(p=1\right.$ quarter and $j^{\max }=60$ days $)$ and a beta lag MIDAS polynomial with the parameter contraint that $a=1$. The model is estimated by NLLS. For brevity we only present the estimates of the (first-order) autoregressive parameter $\rho$, and the loading of the MIDAS polynomials $\beta$. Terms in brackets are the associated (HAC corrected) $t$-stats. Stars indicate significance at the $2.5 \%\left({ }^{* *}\right), 5 \%(* *)$, and $10 \%(*)$ levels (one-sided test). 


\begin{tabular}{|c|c|c|c|c|c|c|c|c|}
\hline & & Oil Prices & Eurostoxx50 & VSTOXX & OIS-1M & OIS-1Y & Slope-10Y/2Y & EUR/USD \\
\hline \multirow[t]{4}{*}{$\mathrm{I} @ \mathrm{R}(5 \%)$} & $\rho$ & $0.881^{* * *}$ & $0.928^{* * *}$ & $0.963^{* * *}$ & $0.885^{* * *}$ & $0.878^{* * *}$ & $0.868^{* * *}$ & $0.878^{* * *}$ \\
\hline & & [15.695] & {$[12.767]$} & {$[18.042]$} & {$[18.864]$} & {$[20.485]$} & {$[18.917]$} & {$[16.806]$} \\
\hline & $\beta$ & 0.245 & 0.676 & $-0.282^{* * *}$ & $5.361^{* * *}$ & $6.176^{* * *}$ & $-9.534^{* * *}$ & 0.272 \\
\hline & & [1.473] & {$[1.556]$} & {$[-2.876]$} & {$[3.514]$} & {$[3.654]$} & {$[-2.907]$} & {$[0.563]$} \\
\hline \multirow[t]{4}{*}{$\mathrm{MPF}$} & $\rho$ & $0.797^{* * *}$ & $0.874^{* * *}$ & $0.856^{* * *}$ & $0.843^{* * *}$ & $0.815^{* * *}$ & $0.821^{* * *}$ & $0.78^{* * *}$ \\
\hline & & [11.735] & {$[13.248]$} & [13.134] & {$[13.221]$} & {$[11.991]$} & [13.959] & {$[9.877]$} \\
\hline & $\beta$ & 0.083 & $0.38 * * *$ & $-0.092^{*}$ & $2.769 * * *$ & $2.98^{* *}$ & $-4.354^{* * *}$ & 0.194 \\
\hline & & {$[1.042]$} & {$[2.784]$} & {$[-1.759]$} & {$[3.425]$} & [2.197] & {$[-2.406]$} & {$[0.736]$} \\
\hline \multirow[t]{4}{*}{$\mathrm{I} @ \mathrm{R}(95 \%)$} & $\rho$ & $0.832^{* * *}$ & $0.85^{* * *}$ & $0.831^{* * *}$ & $0.832^{* * *}$ & $0.825^{* * *}$ & $0.839^{* * *}$ & $0.778^{* * *}$ \\
\hline & & {$[11.917]$} & {$[13.122]$} & {$[13.215]$} & [12.833] & [11.389] & {$[12.784]$} & {$[11.767]$} \\
\hline & $\beta$ & 0.13 & $0.301^{*}$ & -0.095 & $2.644^{* * *}$ & $2.36^{*}$ & $-4.325 * * *$ & $0.728^{* *}$ \\
\hline & & {$[1.224]$} & {$[1.854]$} & {$[-1.565]$} & {$[3.146]$} & [1.689] & {$[-2.295]$} & {$[2.114]$} \\
\hline \multirow[t]{4}{*}{ IQR } & $\rho$ & $0.953^{* * *}$ & $0.93^{* * *}$ & $0.943^{* * *}$ & $0.97^{* * *}$ & $0.974^{* * *}$ & $0.966^{* * *}$ & $0.928^{* * *}$ \\
\hline & & [14.766] & [15.983] & [16.11] & [14.448] & {$[12.256]$} & [13.928] & [15.535] \\
\hline & $\beta$ & 0.134 & -0.086 & -0.058 & $3.61^{*}$ & 3.298 & -5.591 & -0.157 \\
\hline & & [1.004] & {$[-0.604]$} & {$[-1.035]$} & [1.714] & [1.162] & {$[-1.501]$} & {$[-0.816]$} \\
\hline \multirow[t]{4}{*}{$\mathrm{ASY}$} & $\rho$ & $0.634^{* * *}$ & $0.602^{* * *}$ & $0.667^{* * *}$ & $0.493^{* * *}$ & $0.545^{* * *}$ & $0.51^{* * *}$ & $0.558^{* * *}$ \\
\hline & & [8.016] & [7.188] & [7.574] & {$[5.616]$} & {$[7.265]$} & [6.318] & [6.395] \\
\hline & $\beta$ & $0.171^{* * *}$ & 0.155 & $-0.127^{*}$ & $3.777 * * *$ & $3.183^{* * *}$ & $-6.932^{* * *}$ & 0.229 \\
\hline & & {$[2.81]$} & {$[0.915]$} & {$[-1.784]$} & {$[4.534]$} & [3.313] & {$[-4.301]$} & {$[0.67]$} \\
\hline
\end{tabular}

Table 4: Quarterly inflation risks and daily financial variables

The Table presents the estimation results of the autoregressive MIDAS model (3.1) for the various 2Y ahead quarterly inflation risk measures and daily financial indicators. The specification involves an AR(1) autoregressive term $\left(p=1\right.$ quarter and $j^{\max }=60$ days $)$ and a beta lag MIDAS polynomial with the parameter contraint that $a=1$. The model is estimated by NLLS. For brevity we only present the estimates of the (first-order) autoregressive parameter $\rho$, and the loading of the MIDAS polynomials $\beta$. Terms in brackets are the associated (HAC corrected) $t$-stats. Stars indicate significance at the $2.5 \%\left({ }^{* *}\right), 5 \%(* *)$, and $10 \%(*)$ levels (one-sided test). 


\begin{tabular}{rccccc}
\hline \hline & I@R(5\%) & MPF & I@R(95\%) & IQR & ASY \\
& & & & & \\
& End-of quarter forecasts; 1Y ahead indicators \\
\hline Brent Oil & 0.123 & 0.117 & 0.121 & 0.069 & 0.053 \\
Eurostoxx 50 & 0.121 & 0.119 & 0.128 & 0.07 & 0.057 \\
VSTOXX & 0.108 & 0.112 & 0.137 & 0.067 & 0.054 \\
OIS1M & 0.119 & 0.114 & 0.125 & 0.072 & 0.054 \\
OIS1Y & 0.11 & 0.112 & 0.124 & 0.072 & 0.054 \\
Slope 10Y-2Y & 0.108 & 0.107 & 0.122 & 0.071 & 0.053 \\
USD/EUR & 0.131 & 0.133 & 0.138 & 0.07 & 0.058 \\
Average (uniform) & 0.099 & 0.105 & 0.116 & 0.066 & 0.051 \\
Average (BIC) & 0.103 & 0.107 & 0.12 & 0.068 & 0.052 \\
AR & 0.147 & 0.138 & 0.152 & 0.078 & 0.061 \\
RW & 0.152 & 0.144 & 0.157 & 0.075 & 0.067 \\
& & & & & \\
& End-of quarter forecasts; 2Y ahead indicators \\
Brent Oil & 0.087 & 0.057 & 0.069 & 0.115 & 0.049 \\
Eurostoxx 50 & 0.082 & 0.054 & 0.07 & 0.113 & 0.057 \\
VSTOXX & 0.085 & 0.048 & 0.07 & 0.114 & 0.054 \\
OIS1M & 0.074 & 0.053 & 0.07 & 0.113 & 0.052 \\
OIS1Y & 0.074 & 0.052 & 0.071 & 0.107 & 0.051 \\
Slope 10Y-2Y & 0.08 & 0.054 & 0.07 & 0.107 & 0.05 \\
USD/EUR & 0.09 & 0.057 & 0.071 & 0.113 & 0.058 \\
Average (uniform) & 0.07 & 0.048 & 0.067 & 0.105 & 0.046 \\
Average (BIC) & 0.074 & 0.05 & 0.068 & 0.109 & 0.05 \\
AR & 0.099 & 0.065 & 0.083 & 0.179 & 0.061 \\
RW & 0.102 & 0.068 & 0.082 & 0.168 & 0.067 \\
\hline \hline & & & & &
\end{tabular}

Table 5: In-sample forecasting performances

The table reports the RMSE obtained when forecasting the inflation risk measures out-of-sample with the MIDAS models associated to the different financial indicators. The MIDAS regressions involve an AR(1) autoregressive term $\left(p=1\right.$ quarter and $j^{\max }=60$ days $)$ and an exponential Almon lag polynomial as described in equation (6.2). Single financial indicator MIDAS models are combined through two averages (AVG), uniformly and BIC weighted. RMSE are compared with the ones of an AR(1) model and a pure RW model. 


\begin{tabular}{rccccc}
\hline \hline & I@R(5\%) & MPF & I@R(95\%) & IQR & ASY \\
& & & & & \\
& End-of quarter forecasts; 1Y ahead indicators \\
\hline Brent Oil & 0.202 & 0.176 & 0.198 & 0.104 & 0.071 \\
Eurostoxx 50 & 0.195 & 0.176 & 0.199 & 0.103 & 0.078 \\
VSTOXX & 0.205 & 0.19 & 0.21 & 0.104 & 0.08 \\
OIS1M & 0.164 & 0.161 & 0.195 & 0.1 & 0.079 \\
OIS1Y & 0.16 & 0.153 & 0.203 & 0.102 & 0.084 \\
Slope 10Y-2Y & 0.17 & 0.172 & 0.199 & 0.1 & 0.076 \\
USD/EUR & 0.236 & 0.218 & 0.237 & 0.116 & 0.079 \\
MA Average & 0.178 & 0.165 & 0.195 & 0.096 & 0.076 \\
MA Average BIC & 0.179 & 0.169 & 0.201 & 0.097 & 0.084 \\
AR & 0.209 & 0.185 & 0.209 & 0.094 & 0.081 \\
RW & 0.205 & 0.189 & 0.212 & 0.087 & 0.082 \\
& & & & & \\
& End-of quarter forecasts; $2 Y$ & ahead indicators \\
\hline Brent Oil & 0.145 & 0.089 & 0.095 & 0.237 & 0.07 \\
Eurostoxx 50 & 0.13 & 0.093 & 0.1 & 0.247 & 0.075 \\
VSTOXX & 0.15 & 0.092 & 0.1 & 0.238 & 0.062 \\
OIS1M & 0.135 & 0.086 & 0.091 & 0.235 & 0.07 \\
OIS1Y & 0.134 & 0.089 & 0.094 & 0.232 & 0.065 \\
Slope 10Y-2Y & 0.126 & 0.091 & 0.106 & 0.243 & 0.079 \\
USD/EUR & 0.15 & 0.095 & 0.103 & 0.237 & 0.068 \\
MA Average & 0.137 & 0.09 & 0.097 & 0.235 & 0.067 \\
MA Average BIC & 0.136 & 0.094 & 0.097 & 0.231 & 0.075 \\
AR & 0.137 & 0.085 & 0.093 & 0.234 & 0.069 \\
RW & 0.135 & 0.089 & 0.096 & 0.136 & 0.072 \\
\hline \hline
\end{tabular}

Table 6: Out-of-sample forecasting performances

The table reports the RMSFE obtained when forecasting the inflation risk measures out-of-sample with the MIDAS models associated to the different financial indicators. The MIDAS regressions involve an AR(1) autoregressive term $\left(p=1\right.$ quarter and $j^{\max }=60$ days $)$ and an exponential Almon lag polynomial as described in equation (6.3). Single financial indicator MIDAS models are combined through two averages (AVG), uniformly and BIC weighted. RMSFE are compared with the ones of an AR(1) model and a pure RW model. 

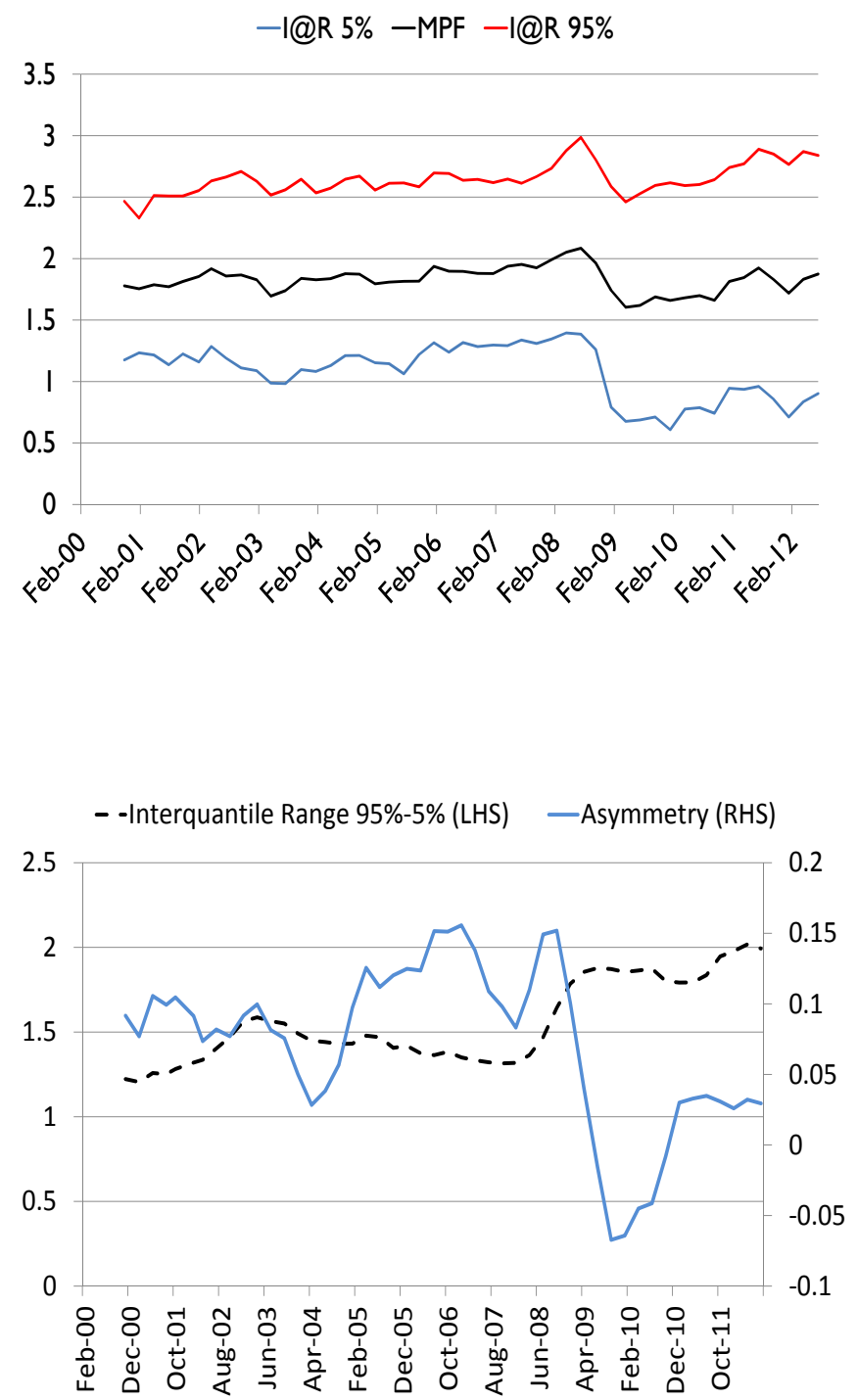

Figure 1: Survey-based inflation risk measures for the euro area

The figure plots the time series of MPF together with I@R(5\%) and I@R(95\%) inflation risk measures (top panel) and the IQR together with the ASY inflation risk measures (bottom panel) for the euro area. For these last two measures, the chart present smoothed data using a moving average over the last 4 quarters. The data cover the 1999Q1-2012Q3 sample. Details on these risk measures appear in Section 2 and Appendix A. 


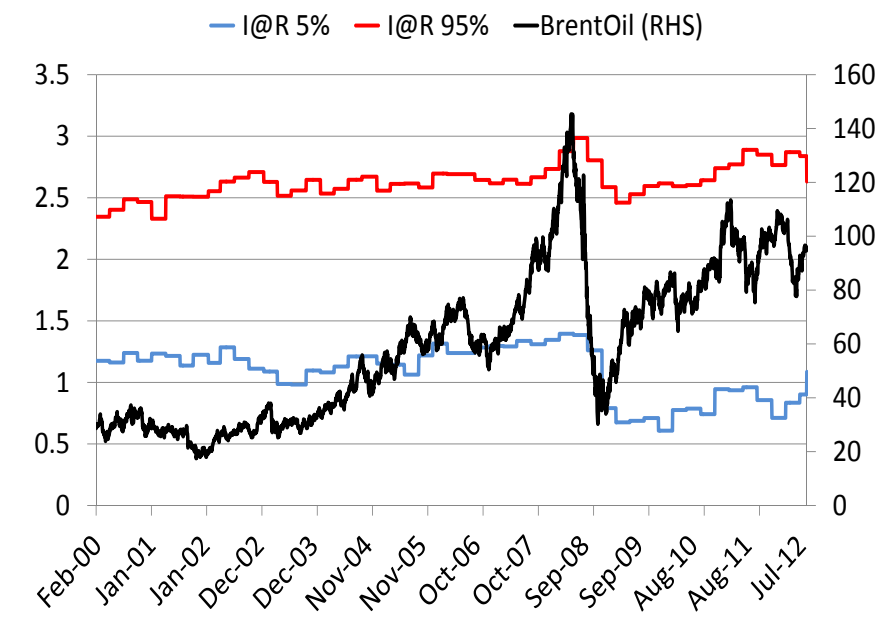

Figure 2: The impact of oil prices on euro area inflation risk measures The figure plots the time series of the Brent Oil price together with the inflation risk measures I@R(5\%) and I@R(95\%) for the euro area. The data cover the 1999Q1-2012Q3 sample. Details on these risk measures appear in Section 2 and Appendix A. 